\title{
Gradhiva
}

GRADHIV

Revue d'anthropologie et d'histoire des arts

17 | 2013

L'esthétique du geste technique

\section{Le Nouvel An chinois à Paris. Sur les scènes de l'altérité}

Staging alterity : the Chinese New Year in Paris

\section{Jing Wang}

\section{OpenEdition}

1 Journals

\section{Édition électronique}

URL : http://journals.openedition.org/gradhiva/2668

DOI : 10.4000/gradhiva.2668

ISSN : 1760-849X

Éditeur

Musée du quai Branly Jacques Chirac

\section{Édition imprimée}

Date de publication : 16 mai 2013

Pagination : 170-193

ISBN : 978-2-35744-049-74

ISSN : 0764-8928

Référence électronique

Jing Wang, "Le Nouvel An chinois à Paris. Sur les scènes de l'altérité », Gradhiva [En ligne], 17 | 2013,

mis en ligne le 28 mai 2013, consulté le 19 avril 2019. URL : http://journals.openedition.org/

gradhiva/2668 ; DOI : 10.4000/gradhiva.2668

Ce document a été généré automatiquement le 19 avril 2019.

(c) musée du quai Branly 


\title{
Le Nouvel An chinois à Paris. Sur les scènes de l'altérité
}

Staging alterity: the Chinese New Year in Paris

\author{
Jing Wang
}

\section{Remerciements}

Cet article a été réalisé dans le cadre des séminaires " Art et performance » conduits par le département de la recherche et de l'enseignement du musée du quai Branly. Je tiens à remercier particulièrement Anne-Christine Taylor, directrice de la recherche, pour son accueil très généreux, Daniel Fabre pour ses conseils tout au long de mon enquête; cet article a également bénéficié des commentaires d'Anne Raulin, Vincent Goossaert et Timothy Brook ; je suis aussi reconnaissante au groupe des boursiers, mes chers collègues, pour leurs relectures ainsi qu'à Maïra Muchnik qui m'a aidée à la mise en forme finale. 
fig. 1 Patrick Zachmann, Préparatifs pour le défilé du Nouvel An chinois, Paris, XIII arrondissement, 1998.

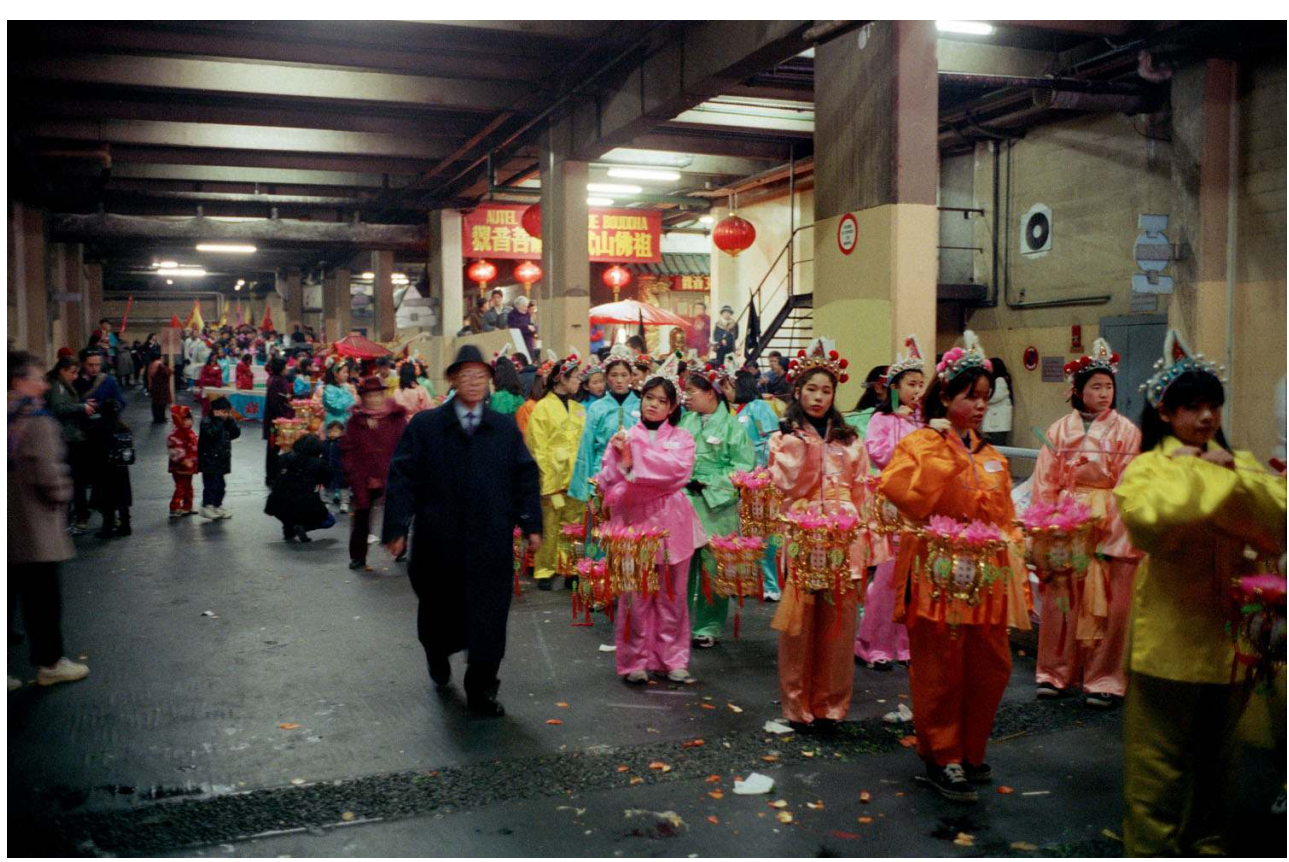

(c) Patrick Zachmann/Magnum Photos.

1 Une culture chinoise est en train de s'inventer à Paris comme dans tous les lieux où la diaspora chinoise s'est installée. Je ne donne pas ici au mot « culture » (en chinois wen hua , 文化) le sens technique, complexe et très discuté, de l'anthropologie, mais celui auquel se réfèrent les Asiatiques de Paris, leurs interlocuteurs politiques, ainsi que les visiteurs et spectateurs du Nouvel An chinois, à savoir : l'expression collective de la différence. Le terme est toujours employé dans un sens positif. Vue du dehors et produite du dedans, la "culture » est célébrée comme un apport précieux à la connaissance réciproque qui fonde des relations sociales harmonieuses. À Paris, les Asiatiques offrent tout particulièrement leur culture en partage à l'occasion du Nouvel An chinois qui est devenu, ces dernières années, l'une des fêtes les plus importantes de la rue parisienne. Près de deux cent mille personnes la suivent, elle met en mouvement plusieurs quartiers parisiens et banlieusards (les $\mathrm{XIII}^{\mathrm{e}}$ et $\mathrm{III}^{\mathrm{e}}$ arrondissements au premier chef, mais aussi Belleville, Aubervilliers et Noisy-le-Grand), mobilise une cinquantaine d'associations, investit tous les espaces de la représentation politique : de la mairie locale jusqu'à l'Élysée en passant par l'Hôtel de Ville de Paris.

Cette culture est en premier lieu une expérience sensorielle. Participer au Nouvel An est l'occasion de voir et d'admirer des spectacles, d'entendre des rythmes musicaux, de suivre des narrations récitées ou mimées, de porter des costumes, d'apprendre pour les uns, et de regarder pour les autres, à danser, à marcher ensemble au milieu des rues débarrassées des voitures, de manger dans les restaurants asiatiques... Pour rendre compte de cette expérience foisonnante, j'ai choisi la piste des objets parce qu'elle permet de mettre en évidence les processus complexes d'institution de la culture qui sont au centre de ma recherche. J'entends par là non pas l'encadrement des activités dites " culturelles » au sein d'institutions officielles, mais le mouvement en cours qui, progressivement, amène à une autonomisation de ces activités et de tous les éléments qu'elles produisent et 
manipulent, leur conférant une valeur éminente en tant que ressource permettant de s'identifier autant comme groupe que comme personne. Je considérerai donc ces objets concrets en tant que nœuds de relation entre les individus qui les mettent en action, leur font jouer des rôles et porter des messages. La piste des objets ouvrira ainsi un parcours de la diversité des scènes où ceux-ci interviennent, et fournira une entrée pour mieux saisir le processus d'institution de la culture chinoise dans le cadre du Nouvel An. En effet, les choses que la fête produit, manipule et anime ont pour caractère principal leur ubiquité: on les retrouve à Paris dans les lieux les plus divers où elles jouent dans des pièces très différentes. Points stables de la description que je propose, ces choses font alors ressortir davantage ces différences, mettant en évidence non seulement la variété des pratiques que le terme unanime de «culture » recouvre dans le cadre du Nouvel An chinois, mais surtout la complexité qui gouverne ici son institution.

\section{Prélude : ombres et lumières au musée}

3 J'avais déjà commencé l'ethnographie du Nouvel An chinois quand mon attention a été attirée vers la question des objets qui, sans être totalement absente de mon observation, n'y occupait pas néanmoins une place déterminante. En fait, c'est une sollicitation extérieure qui m'a mise sur la voie. Dans le cadre du projet Asemus-Virtual Collection of Masterpieces $^{1}$, il fallait réaliser un film sur la collection asiatique du musée du quai Branly. Sollicitée pour concevoir cette présentation, je proposai de mettre en valeur tout ce qui pouvait évoquer la grande fête des Asiatiques de Paris. Je ne trouvai dans les vitrines du plateau des collections que quelques costumes des minorités du sud de la Chine et de la péninsule Indochinoise dont les qualités plastiques exceptionnelles avaient retenu l'attention des conservateurs. La plupart des objets venus de Chine et de l'aire d'influence chinoise étaient dans les réserves; réserves visibles de la colonne centrale pour les instruments de musique, réserves cachées pour tout le reste. J'en explorai l'inventaire et y trouvai à peu près tout ce que je cherchais : figures de héros et de divinités que le Nouvel An met en évidence ${ }^{2}$, modèles réduits de dragons et de lions, papiers découpés portant des vœux de bonne année. L'essentiel était donc là, muni de ses numéros d'inventaire. Il me suffit de demander une autorisation écrite aux responsables des collections pour voir apparaître, soigneusement emballés dans du papier de soie et maniés avec des gants de fil blanc, ces papiers, statues et maquettes datant, tout au plus, des années 1880 : « Le musée du quai Branly n'est pas le musée Guimet, m’a-t-on expliqué, presque tout ce que nous avons vient de voyageurs, administrateurs et ethnographes surtout intéressés aux artisanats populaires, sans grande valeur antiquaire. » Les objets sortaient donc de leur discrétion à l'occasion de cette sorte de clip où je jouais le rôle de présentatrice ${ }^{3}$. C'était, au fond, une petite exposition filmée dont j'étais le guide. Puis les objets sont retournés dans la nuit et le silence des réserves.

\section{Des objets en mouvement}

4 On pourrait légitimement décrire la longue parade du Nouvel An chinois comme une sorte de théâtre ambulant dans lequel, pour la grande majorité des acteurs, il s'agit de donner vie à un vaste dépôt d'objets stockés toute l'année par les associations organisatrices. Je me limiterai ici au XIII ${ }^{e}$ arrondissement, le lieu le plus ancien et, sur tous les plans, le plus riche. Le défilé se déroule le dimanche qui suit le premier jour de l'année 
lunaire. Sa forme est, à première vue, très simple : dans les rues principales, pendant un après-midi qui s'arrête impérativement à dix-huit heures (nous verrons pourquoi plus loin), défilent des associations. Chacune, selon un dispositif bien encadré, présente la performance qu'elle a choisie, la marche, toujours ouverte par les officiels, étant précédée d'une banderole à son nom. On peut se déplacer à pied ou sur la plateforme d'un camion ; marcher, danser ou bien faire une démonstration d'arts martiaux; se faire accompagner de rythmes joués en direct ou d'une mélodie enregistrée. Cependant, mis à part pour les notables en tenue de ville, le costume exotique est obligatoire. C'est là que nous retrouvons l'immense répertoire des façons de s'habiller - anciennes, théâtrales et régionales - qui définit l'apparence chinoise pour les organisateurs et les spectateurs. Une apparence qui réunit toutes les diversités sans se soucier d'une quelconque exactitude historique. Deux références dominent cependant. D'une part, les costumes de l'Opéra de Pékin, tradition prestigieuse née à la fin du XVIII ${ }^{\mathrm{e}}$ siècle, avec ses récits, ses musiques, ses chants et ses codes vestimentaires théâtraux ${ }^{4}$; d'autre part, les costumes des "minorités ethniques » : la Chine en revendique cinquante-six, dont beaucoup sont aussi présentes dans la péninsule Indochinoise (Laos, Cambodge, Vietnam) d'où viennent la plupart des Asiatiques du Chinatown parisien ${ }^{5}$.

Le défilé du Nouvel An réveille cette gigantesque garde-robe puisque quelque deux mille costumes sont distribués aux acteurs, selon un processus particulier qui va nous conduire à l'intérieur des associations. Celles-ci sont toutes nées ou se sont recomposées après 1975, avec l'arrivée des réfugiés du Sud-Est asiatique fuyant les guerres et les régimes autoritaires. Elles regroupent les originaires au sens large; la plus puissante se nomme encore, par exemple, "Association des résidents en France d'origine indochinoise" (Arfoi). Elles se sont multipliées par scissions internes jusqu'à atteindre aujourd'hui un total d'une vingtaine, toutes présentes dans le défilé. Nées de la nécessité d'offrir à l'émigrant un accueil solidaire en l'aidant pratiquement dans toutes ses démarches administratives et en lui donnant les rudiments de la langue française, elles sont davantage aujourd'hui des associations à vocation culturelle, tout en continuant d'alimenter plus ou moins efficacement les liens sociaux et économiques entre leurs membres. Des cours de langue et d'écriture chinoise, de cuisine, de chant, de danse et d'arts martiaux, destinés aux deuxième et troisième générations nées de l'immigration, constituent désormais l'essentiel des activités. On peut aller jusqu'à affirmer que, depuis le milieu des années 1990, des associations où l'on apprenait d'abord aux nouveaux venus à se débrouiller en France sont devenues des lieux où l'on explique à leurs enfants et petits-enfants ce qu'est la Chine, ou plutôt la "culture chinoise ». Leur fonction initiale s'est donc exactement inversée ${ }^{6}$. Le Nouvel An est le moment clé de cette transmission. Comme me le disent mes interlocuteurs: «On se sent chinois au moins une fois dans l'année, le jour du défilé. »

6 Soigneusement repassés et pliés par les femmes les plus anciennes, les costumes du Nouvel An sont glissés dans des housses et serrés dans des cartons qui forment comme de gros ballots. Chaque association conserve, souvent dans les recoins de son local, de vieux cartons qui ont contenu des produits alimentaires et portent des étiquettes surprenantes: empereur, concubines, guerriers, Miao, Tai, Lao... Tous ces vêtements viennent de Chine où ils ont été payés fort cher pour les plus beaux d'entre eux. L'acte le plus important qui inaugure le temps du Nouvel An est leur distribution aux acteurs, qui se prépare dès le mois de novembre. L'association tient, lors de ses permanences, un cahier sur lequel viennent s'inscrire les garçons et les filles candidats. Beaucoup sont du 
quartier et liés au monde des associations chinoises mais il n'y a aucune obligation d'appartenance ni même d'origine. Français de souche, Antillais, Maghrébins, Africains ne sont pas rares sous les costumes du Nouvel An. Bien sûr, une hiérarchie existe et ce sont, généralement, les parents d'origine chinoise qui veillent à ce que leurs enfants portent les costumes les plus prestigieux. Un certain nombre de fidèles aimeraient bien retrouver les costumes qu'ils ont portés fièrement l'année précédente, mais ils ont grandi entre-temps. Il faut alors adapter aux diverses morphologies une collection faite d'échantillons de toutes tailles. Ce qui donne lieu à des séances d'essayage très animées au siège même de l'association. Pour les acteurs du défilé, la fête est déjà là. J'ai tenté, à l'aide de questionnaires, de caractériser cet ensemble mouvant des jeunes costumés. Je dois dire que les réponses confirment l'extrême diversité des origines et des motivations (au nombre desquelles la modeste «enveloppe rouge: hongbao, 红包» remise à chaque figurant, rémunéré entre quarante et quatre-vingts euros). En fait, l'essentiel ici me semble être la nécessaire mise en mouvement de cet ensemble. Pour la majorité des participants, celle-ci ne comporte rien d'autre que le fait de porter le costume et de marcher avec, en bon ordre, pendant cinq heures, souvent par un temps glacial. Mais aux côtés de ces modestes fantassins, d'autres animateurs d'objets tiennent un rôle bien plus engagé.

7 En effet, de façon ponctuelle, tout au long du défilé, des musiciens - uniquement des percussionnistes - accompagnent la marche. Le batteur du gros tambour mène le groupe, mais chaque cymbaliste, garçon ou fille, a dû répéter sa partie pendant quelques séances. Beaucoup de marcheurs costumés envient ces répétitions et déplorent de ne pas y avoir participé. Pour eux, elles sont la marque d'une plus grande implication dans une fête où, pourtant, eux-mêmes occupent déjà une place très visible. Mais d'autres acteurs ont dû faire un plus long apprentissage de la relation à l'objet qu'ils ont la mission d'animer, ce sont les porteurs des dragons et les danseurs des lions. Les uns et les autres incarnent au plus haut point l'expérience personnelle de la fête : devenir un autre que soi en donnant à une figure d'animal une vie - il se met à bouger -, une action - il intervient directement dans la conquête et le découpage des espaces - et enfin une expression - il réagit à des situations d'échange. Avec les dragons et les lions, la fête devient rite, manifeste des forces, entraîne des effets. Ces objets lui sont propres et indispensables. Dragons et lions dament le pion aux masques réservés à un seul acteur - il n'y a qu'un masque individuel dans le Nouvel An parisien, celui dit du "Bouddha souriant", une sorte de grosse tête portée par un garçon de petite taille - puisqu'ils ne peuvent exister qu'en "avalant » littéralement plusieurs acteurs qui coopèrent pour les animer. 
fig. 2 La veille du défilé, les chars décorés attendent dans le parking, devant le temple de l'A.R.F.O.I (Association des Résidents en France d'Origine Indochinoise), 2012.

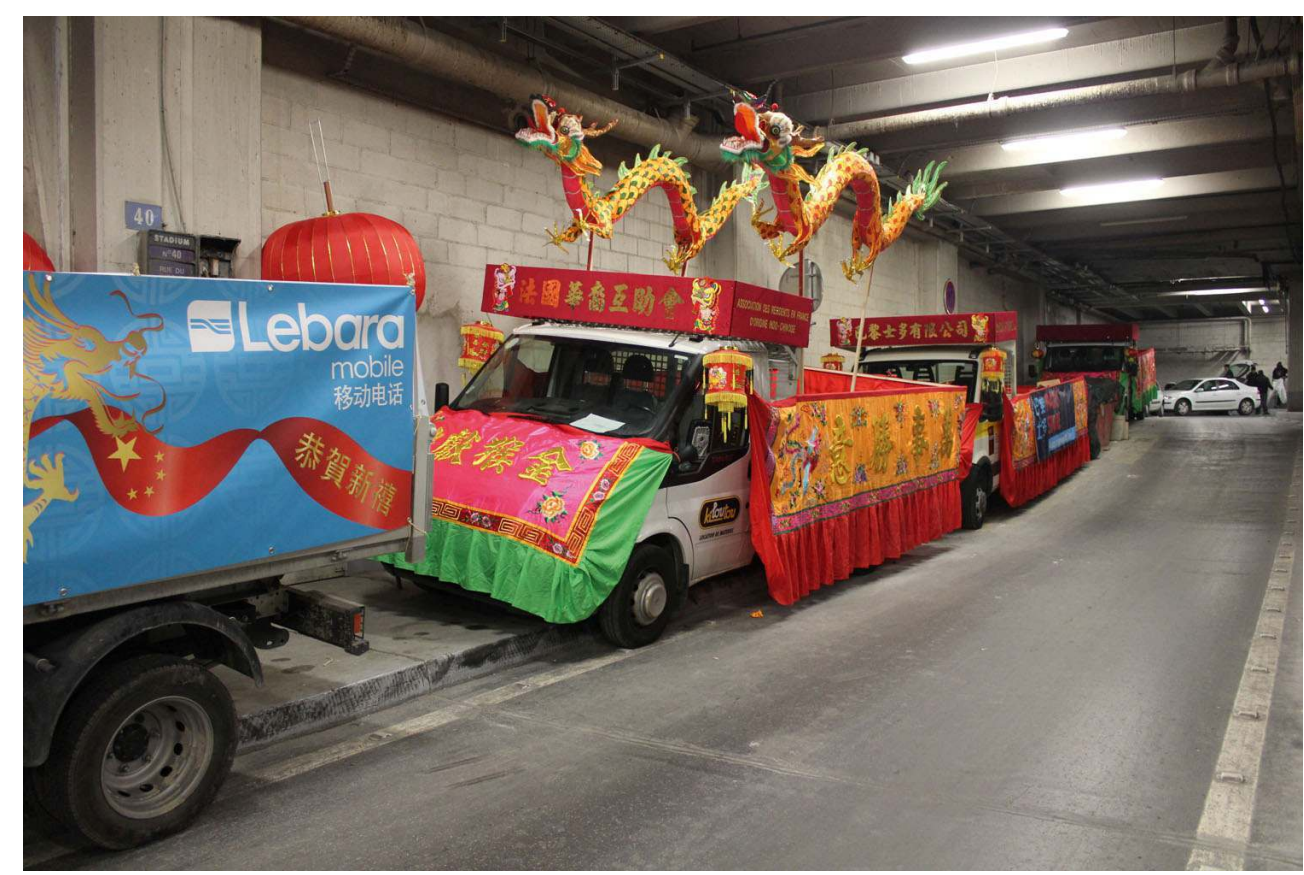

(c) Photo Jing Wang.

8 Il y a pourtant une différence entre dragons et lions, tenant à l'engagement des acteurs. Les dragons sont de très grandes bêtes de toile portées par une douzaine de garçons, chacun ayant la charge de tenir à bout de bras et de mouvoir une portion de la longue queue articulée qui forme un corps d'une quinzaine de mètres. L'animal est très visible, et ses mouvements d'ondulation, de haut en bas et de droite à gauche, ainsi que ses accélérations soudaines doivent être parfaitement synchronisés. Son action échappe à l'ordre immuable du défilé puisqu'il est libre de se déplacer en marge du cortège et même de fendre la foule des spectateurs. Son déplacement accompagne le défilé sur ses marges ou bien s'interpose entre deux associations. Deux positions rendues possibles par le fait que défilé et dragon sont exactement de même forme, découpés l'un et l'autre en modules ou en tronçons. Au fond, la rigidité ordonnée du défilé atteint une relative liberté de mouvement sous l'apparence des dragons dont le nombre tend, ces dernières années, à se multiplier, devenant une attraction très remarquable. Si le dragon joue un rôle important, l'intervention d'un meneur expérimenté suffit cependant à organiser la performance. J'ai suivi l'un d'eux tout au long d'un hiver, et l'ai vu recruter ses amis et les entraîner dans un gymnase ou un parking. Lui seul est payé par l'association qui l'engage et chargé de répartir les gains entre tous les porteurs.

9 L'animation du lion requiert quant à elle d'autres qualités, véritablement sportives. Dès la première manifestation publique spectaculaire du Nouvel An chinois en 1983, le lion a joué d'emblée un rôle plus important puisque, pendant la quinzaine de jours où le quartier vit au diapason du Nouvel $\mathrm{An}^{7}$, il est indépendant du défilé. Il accomplit un rite relativement complexe devant les commerces et les restaurants. Deux acteurs donnent vie à l'animal, l'un solide, l'autre plus léger qui grimpe sur les épaules de son camarade et anime la tête très expressive du lion. Le groupe comprend également des musiciens (tambour et cymbales) et quelques masques de Bouddha souriant. Le lion se présente 
devant un magasin, où il est accueilli par le patron qui l'invite à entrer pour saluer l'autel des ancêtres et celui d'une divinité : Tudigong (土地公), dieu du sol, ou encore Guan Yu (ou Guan Di, 关帝), un héros guerrier présent dans la plupart des magasins car les commerçants apprécient beaucoup sa protection. À la sortie, débute la performance : le lion saute et danse, il reçoit une salade qui pend au bout d'une perche et qu'il avale goulument en manifestant sa joie par de multiples mouvements du visage (bouche, yeux, oreilles). Le patron tend au meneur de la troupe une enveloppe rouge contenant son offrande. En échange, la simple visite du lion qui danse lui apporte la protection divine, la prospérité et, très certainement, la reconnaissance et le prestige pour avoir offert ce spectacle au public massé devant sa vitrine. Quand l'échange symbolique est terminé, le patron allume un énorme chapelet de pétards suspendu devant sa porte et le lion s'éloigne au milieu des explosions et de la fumée. Effectuée pour la première fois en 1983 par un seul groupe, déjà dédoublée en 1984, la danse s'est transmise de maîtres en élèves, aboutissant à la prolifération actuelle des lions dans le défilé : quatre ou cinq groupes, une douzaine d'animaux recréés avec un incontestable talent, résultat de longues séances de répétition dans les salles de sport du quartier auxquelles prennent part les jeunes praticiens de kung fu qui s'entrainent tout au long de l'année.

10 Ainsi, du figurant occasionnel au virtuose de la danse du lion, le défilé du Nouvel An distribue ses rôles et produit un ensemble constamment enrichi au fil des ans mais toujours maîtrisé selon un ordre descendant: les consignes qui canalisent la prestation des acteurs se diffusent très vite par l'intermédiaire d'une foule de médiateurs, vêtus d'un ciré jaune, qui savent ce qu'il convient de faire et guident les débutants sur cet immense théâtre. Comme dans toute cérémonie de cette taille, des tensions peuvent apparaitre, aussitôt calmées au nom du discours général qui enveloppe cette fête et la présente partout comme un moment d'harmonie où toutes les disputes s'apaisent, où toutes les frictions sont immédiatement résolues, où tout est partage.

\section{La bataille des icônes}

11 Le spectateur ordinaire, même s'il habite le quartier et appartient à la "communauté chinoise » qui accueille les Parisiens ce jour-là, doit se contenter d'admirer l'efficacité des créateurs de la fête. Ceux-ci sont peu exposés et ne sont guère repérables mais un « esprit » d'organisation domine à tous les instants, qui se manifeste par des milliers d'interventions régulatrices. Pourtant une certaine anxiété est perceptible, presque palpable dès que l'on s'approche du cœur caché de la cérémonie et du centre d'où part l'énergie organisatrice.

12 Tout part d'un temple et tout y revient ${ }^{8}$; un temple modeste, caché sous la dalle des olympiades au pied des grands immeubles modernes du quartier, auquel on accède en descendant à l'intérieur d'un parking souterrain. Création de M. Y., principal mécène de la fête et propriétaire d'un des deux grands magasins du quartier', c'est le siège d'une des associations dominantes, l'Arfoi, citée plus haut. Le temple et ses desservants, laïcs, ont la charge très importante d'ouvrir le défilé, de l'accompagner tout le long de son parcours et enfin d'y mettre un terme. Ce pouvoir est incarné dans la statue d'un dieu taoïste: Xuantianshangdi (立天上帝). Cette statue est la plus vénérée du temple, elle a une histoire particulière, liée à ce groupe et à ce lieu. 
fig. 3 Femmes nettoyant la statue du Dieu Xuantianshangdi, dans le temple de l'A.R.F.O.I (Association des Résidents en France d'Origine Indochinoise), 2011.

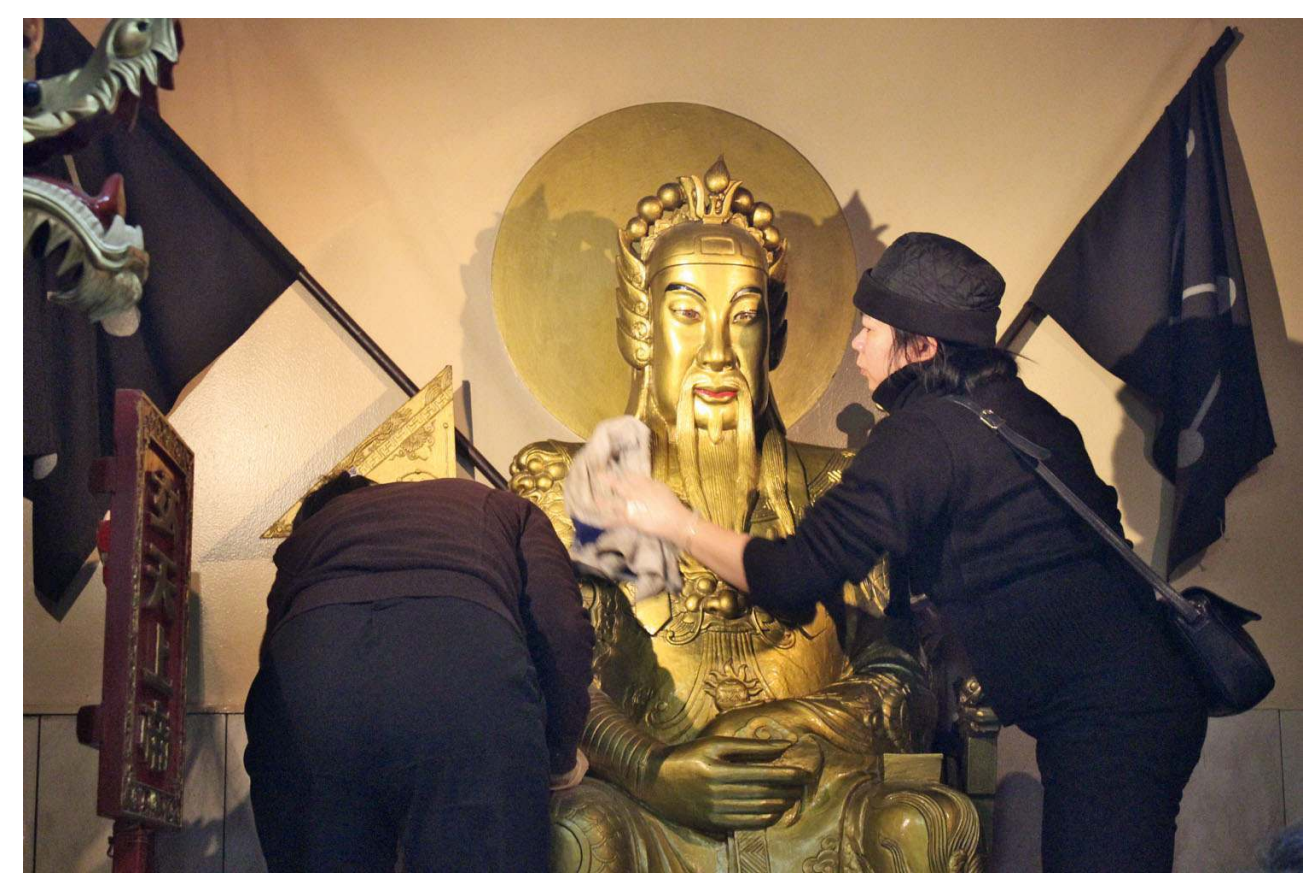

(c) Photo Jing Wang.

Créée en 1982 dans un appartement du quartier, l'Arfoi, composée de Chinois issus du sud de la province de Guangdong et passés principalement par le Cambodge, a acquis son local, 37, rue du Disque, en 1986. Aussitôt naît l'idée d'installer là un temple, le premier du quartier. Mais il faut mettre celui-ci sous la protection de divinités. La commande, en Chine, d'un bouddha et d'un dieu taoïste occupe trois envoyés de l'association au cours de plusieurs voyages entre Paris, Shantou, Chaozhou et Hongkong. Leur choix est arrêté après la visite de la pagode du mont Xuan Wu, près de la ville de Li Feng, province de Canton. C'est de là que viennent les deux principales statues du temple - Bouddha Guanyin (guanyin pusa, 观音菩萨), aux traits féminins, et Xuantianshangdi en vieux sage fidèlement reproduites par un célèbre artisan de Chaozhou; quelques commerçants du quartier en ont payé la fabrication et le transport. Elles ont été installées le 29 janvier 1989 lors d'une somptueuse cérémonie de consécration. Du haut de ses deux mètres, installée sur son autel, la statue massive de Xuantianshangdi regarde vers le sud et domine le temple. Elle est descendue de son autel à onze heures le matin du défilé. Les femmes en profitent pour laver à grande eau son emplacement. On la sort du temple vers treize heures pour la glisser à la fin du cortège (ou plutôt de la procession) deux heures plus tard. Pendant tout l'après-midi, elle est à hauteur d'homme, accompagnée par les fidèles qui la poussent, la touchent, la caressent, lui offrent des oranges et de l'encens, et distribuent des poignées de riz. Xuantianshangdi doit être revenu dans sa "maison" avant la fin du jour, c'est-à-dire avant dix-huit heures (n'oublions pas en effet que nous sommes en janvier-février et que la nuit tombe tôt), sonnant alors la fin du défilé. La sortie du dieu, sa déambulation et son retour suscitent une forte émotion collective. Les porteurs sont très attentifs, la statue est aussi vivante et fragile qu'un corps, elle ne doit pas cogner ni même toucher le sol ou le chambranle de la porte. Pendant tout le temps que dure le défilé - une bonne heure - et que son cortège passe devant le temple, invisible dans les profondeurs de son parking, les percussionnistes varient les rythmes, les 
bannières claquent au vent et leurs porteuses, des jeunes filles costumées, restent immobiles devant la statue. Dès que les officiels - le président de l'Arfoi, le représentant de l'ambassade de Chine, les élus municipaux, le député de l'arrondissement, les adjoints au maire de Paris et même, en 2012, François Hollande, alors candidat à la présidence de la République - ont apposé leurs marques rouges sur le front des dragons qui vont accompagner le dieu ${ }^{10}$, les chapelets de pétards éclatent et la statue se met en marche, accompagnée d'une incessante agitation. À son retour, la fièvre que suscite le dieu n'est pas retombée et il n'est pas rare qu'une vive discussion éclate sur la manière de ranger autour de sa statue les attributs - en particulier les bannières - restés dans le temple. Voici donc un "objet» d'une extraordinaire importance pour certains, certes moins nombreux que ceux qui défilent et beaucoup moins encore que ceux qui regardent le défilé et ne perçoivent rien de son rayonnement.

Depuis quatre ans, une scène insolite est venue s'insérer dans l'ordre rituel du défilé, adoptant elle aussi le langage de l'objet et que j'ai baptisée « la bataille des icônes ». Seuls les organisateurs de ce vaste défilé sont en mesure de percevoir l'affrontement en question, et surtout, d'en comprendre le sens; un sens révélateur des jeux de pouvoir à l'œuvre dans le Nouvel An qui ne peuvent s'énoncer qu'à travers l'animation agonistique d'objets, comme nous allons le voir à travers l'ethnographie très précise de ce qui se passe. Nous sommes près de l'église Saint-Hyppolite, sur le parvis où a pris place le dieu Guan (il s'agit de l'empereur Guan, héros du III ${ }^{\mathrm{e}}$ siècle, également appelé Guan Di [关帝] ou Guan Yu [关羽]), que nous avons déjà rencontré dans les commerces du quartier où le lion vient lui rendre hommage. Il ne figure dans aucun des programmes du défilé, ce qui peut sembler étonnant au vu du spectacle très considérable qu'il suscite. Sa statue de bronze mesure environ un mètre quatre-vingts et ses pieds sont écartés à la même largeur que ses épaules. Son visage a l'air extrêmement tendu et furieux. Trois dragons ornent sa tunique. Sur son buste est posée une tête de face, bouche ouverte, et deux autres dragons, de profil, flottant autour de ses genoux, se battent pour attraper une boule de feu. Entre ses pieds est figuré un grand lingot d'or ; une seconde petite statue de Guan Di, le visage rouge, veille près de lui. Le dieu est fortement protégé. Il est entouré sur une scène fixe, tout à fait unique dans le défilé -, à droite, d'une troupe de musiciens habillés de rouge, le visage revêtu de masques souriants représentant des moines qui jouent avec beaucoup d'entrain du tambour, d'un gong et de deux cymbales. À gauche, deux lions - un rouge et un noir - se tiennent sur deux poteaux. Un dragon rouge va et vient devant cet ensemble, sur le chemin du défilé. D'où sortent ces acteurs incontestablement très entraînés? Ils appartiennent tous à deux associations : Guo Shi Shao Lin (享氏氏少林, Arts martiaux de la famille Guo) et Yeng Mow Tang (association Lion Dance franco-asiatique). Les deux associations entretiennent une relation de quasifiliation - le responsable de l'association de la danse du lion, Jean, pratique les arts martiaux dans l'association de M. R. depuis l'âge de 6 ans. Il y a perfectionné sa technique pendant une vingtaine d'années, mais il a surtout gagné la confiance du maître. En 2007, M. R. lui a ainsi confié l'entraînement de la danse du lion. C'est la raison pour laquelle le frère aîné de Jean gère le dragon rouge présent le jour du défilé. 
fig. 4 et 5 Séance d'entrainement pour la danse du lion, Association française de danse du dragon et lion chinois, l'une des associations culturelles et sportives du $13^{\text {ème }}$ arrondissement parisien parmi celles qui s'entraînent régulièrement à cette danse, et dont beaucoup sont très présentes pendant le défilé, 2011.
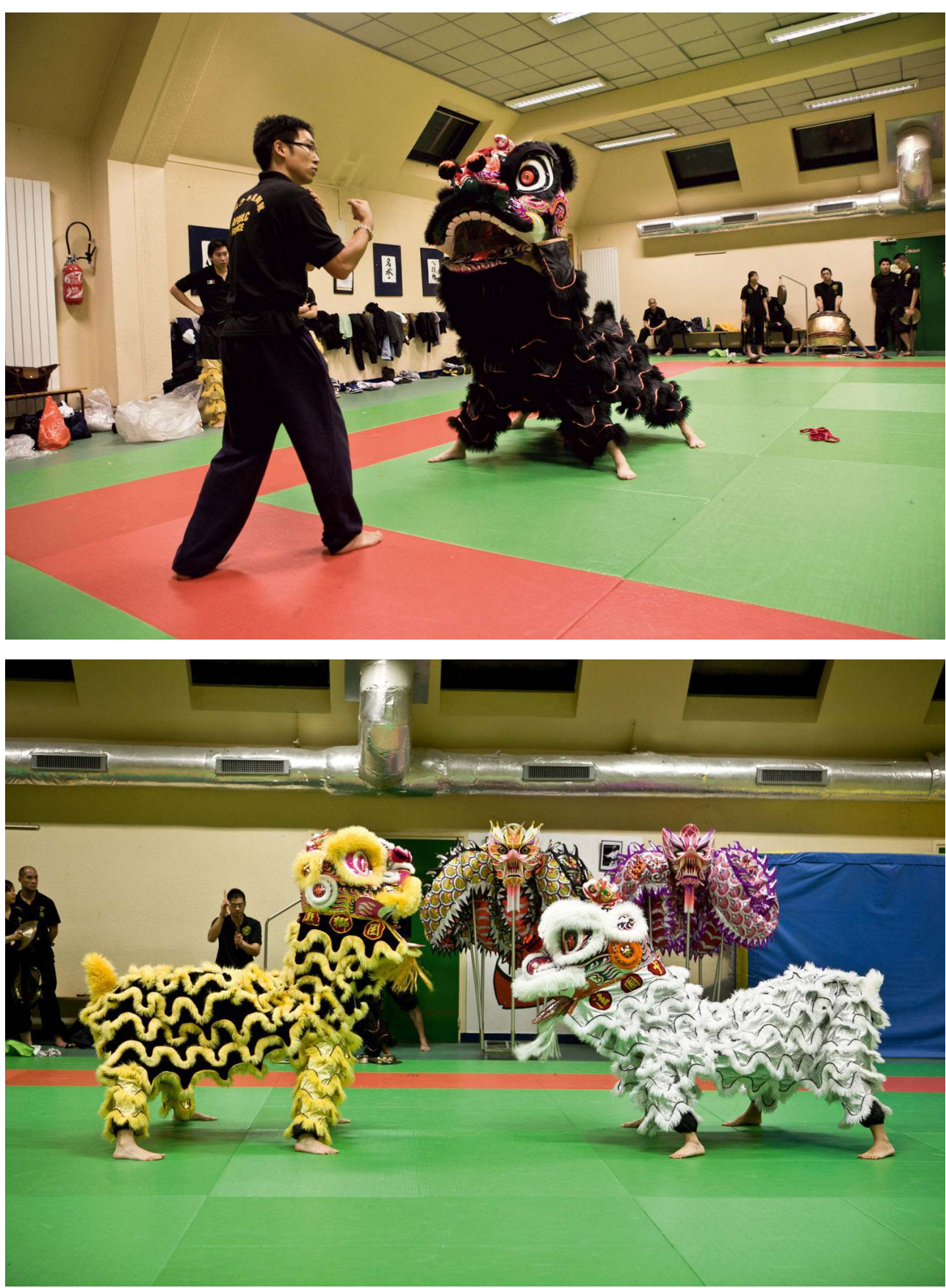

(c) Mathieu Génon. 
fig. 6 Séance d'entraînement pour la danse du lion, Association française de danse du dragon et lion chinois, l'une des associations culturelles et sportives du $13^{\text {ème }}$ arrondissement parisien parmi celles qui s'entraînent régulièrement à cette danse, et dont beaucoup sont très présentes pendant le défilé, 2011.

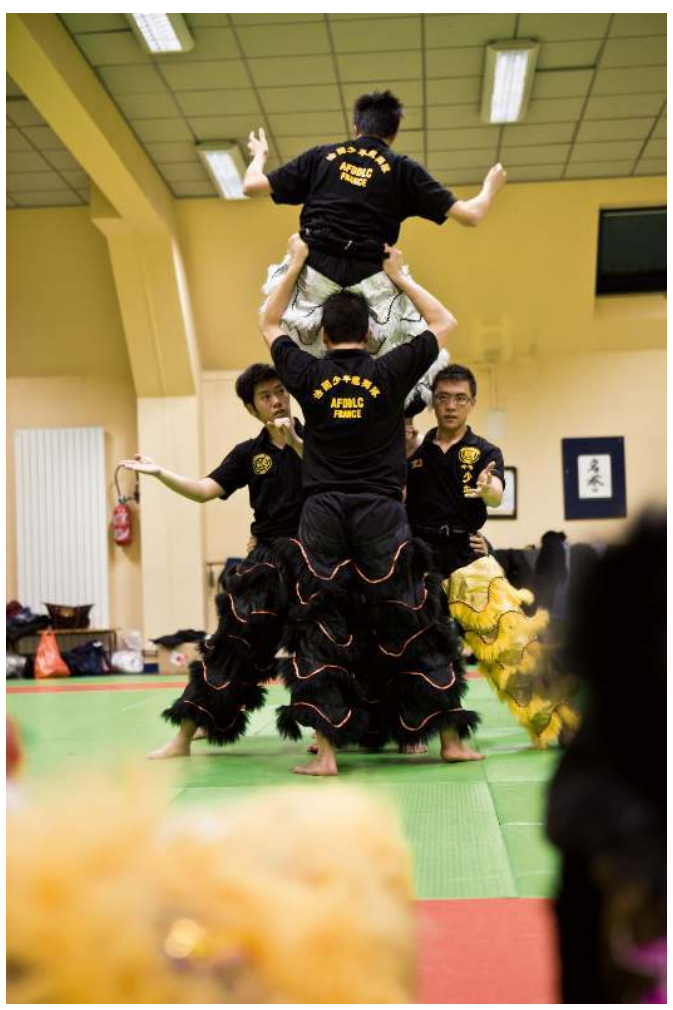

(C) Mathieu Génon.

15 À quoi s'occupe ce groupe qui ne bouge pas pendant que tout le monde marche? Ils s'efforcent, tout simplement, d'imposer à l'ensemble du défilé un rite discret de soumission. Je dis bien rite discret car il prend la forme d'un antagonisme joué entre les lions et les dragons. En effet, comme nous l'avons vu, plusieurs associations sont accompagnées, au cours du défilé, de leur propre dragon ou de leur propre lion. Dès que Jean, juché sur son poteau, voit arriver un de ces deux animaux, il lance la musique et la danse de ses deux lions, particulièrement spectaculaires avec leurs yeux qui clignotent, leur bouche qui s'ouvre, leurs oreilles qui bougent. Les lions qui arrivent s'immobilisent au pied des poteaux. Alors commence une confrontation réglée où chacun cherche à montrer ses capacités acrobatiques. Il en est de même lorsque c'est un dragon qui se présente, mais c'est alors le frère de Jean qui mime contre lui un combat victorieux, là encore selon des règles scéniques très particulières : les deux dragons se disputent une boule multicolore qu'un porteur fait tourner devant leurs gueules. Dans les deux cas, les dragons et les lions vaincus viennent saluer la statue de Guan Di dont le manteau figure, on s'en souvient, la même scène de combat rituel entre dragons. Les dirigeants des associations et ceux qui marchent avec eux sont également invités par l'un des moines (vêtu d'une robe jaune safran, portant une grosse tête ronde et que, dans le groupe, on appelle Bouddha) à venir s'incliner devant le dieu Guan Di et à lui offrir de l'encens. Une fois cette salutation accomplie, la voie est libérée. Évidemment, ces scènes répétées pourraient ralentir le défilé, ce qui ne manque pas de préoccuper les organisateurs. Les spectateurs perçoivent dans cette performance une remarquable démonstration des 
techniques de la danse et de la musique, mais il s'agit aussi de tout autre chose : d'une compétition réelle, d'un véritable combat entre lions et dragons qui finit toujours par le salut des soumis devant la statue de Guan Di.

fig. 7 Patrick Zachmann, Défilé du Nouvel An chinois, Paris, XIII arrondissement, 1986.

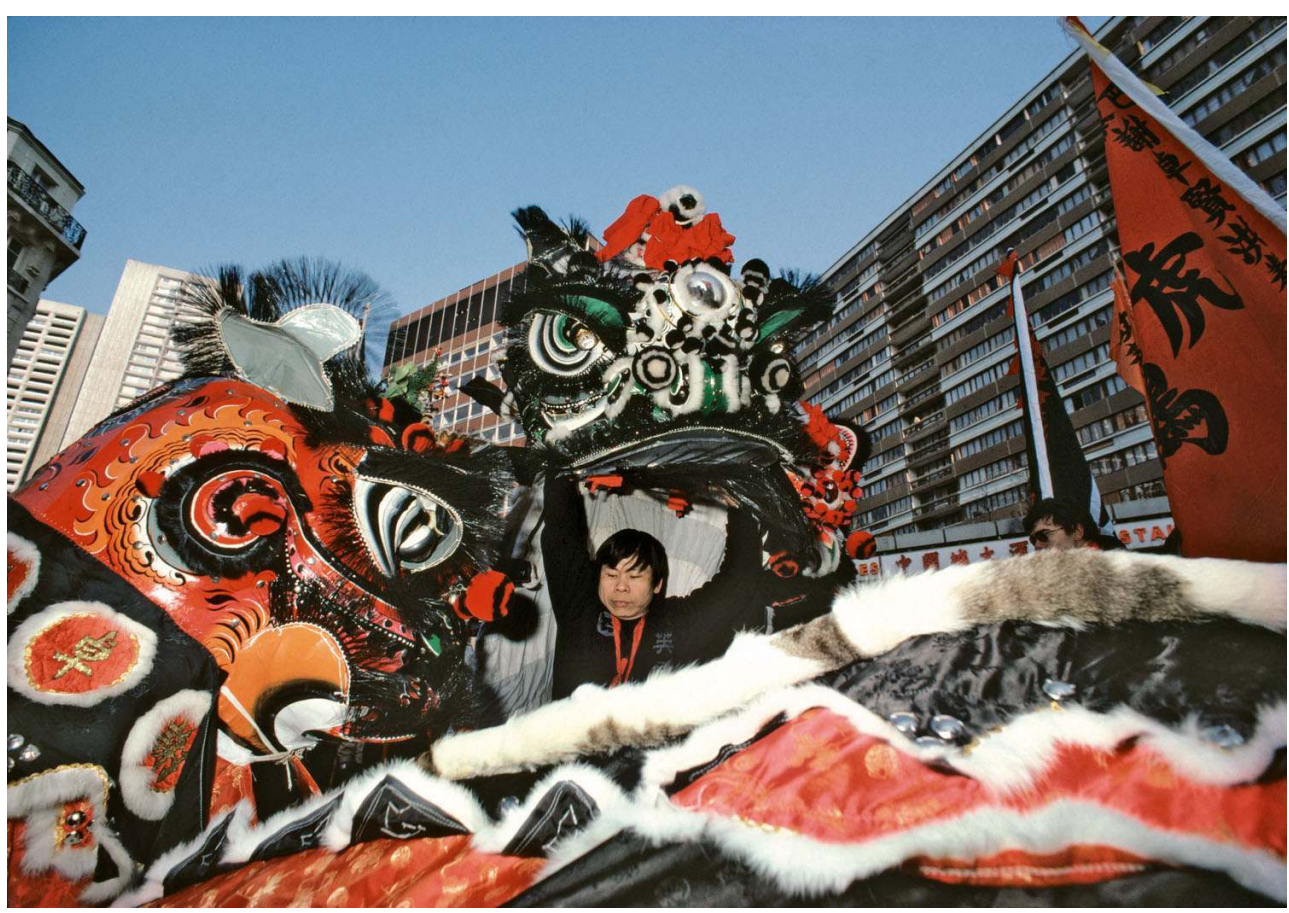

(c) Patrick Zachmann/Magnum Photos

Mais soudain, l'atmosphère change. Les musiciens s'empressent de ranger leurs instruments, le frère de Jean cache Guan Di sous une pièce de tissu bordeaux, Jean enlève sa peau de lion et demande à son collègue de faire de même et de descendre du poteau. Ils poussent vite le chariot et mènent la statue vers le square derrière l'église. Le dragon suit. Je m'étonne de cette brusque disparition, le public est déçu également. Le défilé n'est pourtant pas fini, un autre groupe compact s'approche. Pourquoi se sont-ils précipités pour quitter la scène? Qui arrive ? En fait nous découvrons bientôt, entourée d'une petite foule très fervente, la dernière statue du défilé, le dieu Xuantianshangdi, que j’ai déjà présenté. Pourquoi Guan Di doit-il se cacher lorsque Xuantianshangdi arrive? Quel est le rapport entre ces dieux, leurs statues et, comme nous allons le découvrir, leurs patrons?

$17 \mathrm{Au}$ début, le dieu Guan Di ne faisait pas partie du défilé. Cette statue et les deux associations d'arts martiaux qui l'entourent et l'animent sont soutenus par M. N., originaire de Chaozhou, "patron" d'un temple et actuel propriétaire d'un grand restaurant chinois de Belleville. Selon mes interlocuteurs, jusqu'aux années 1980, M. N. vivait dans le premier Chinatown parisien (celui du XIII ${ }^{\mathrm{e}}$ arrondissement) et y menait de grandes affaires. On sait que la restructuration urbaine de Belleville dans les années 1970 et au début des années 1980 a fourni une grande quantité de logements vides. Rapidement, après la vague des immigrations juive et maghrébine, de plus en plus d'Asiatiques s'y sont installés. Parmi eux, les Chinois de la ville de Chaozhou, l'une des communautés asiatiques $d u \mathrm{XIII}^{\mathrm{e}}$ arrondissement. Leurs activités principales sont la restauration, l'alimentation et les ateliers de confection. M. Y. et M. N. étaient alliés mais ont rompu peu de temps après l'achat du temple de Xuantianshangdi par le premier. En 
1987, M. N. a ouvert le premier grand restaurant chinois de Belleville, ce qui le met en position de fondateur du second Chinatown de Paris. Mais cette suprématie n'a pas duré. Les originaires de Wenzhou, dominants dans le $\mathrm{III}^{\mathrm{e}}$ arrondissement de Paris, sont arrivés et se sont implantés rapidement grâce à leurs réseaux d'entraide ${ }^{11}$. D'une part, M. N. doit faire face à ses concurrents à Belleville et, de l'autre, ses compatriotes du XIII ${ }^{\mathrm{e}}$ arrondissement le tiennent toujours à distance. Pour preuve, cet article publié dans le journal chinois de Paris, New Europe (Ouzhoushibao, 欧洲时报), à l'occasion des festivités $\mathrm{du}$ soixantième anniversaire de la République populaire de Chine en 2009: tous les patrons importants originaires de Chaozhou ont été associés à l'événement, sauf $\mathrm{M}$. N. C'est dans ce contexte que ce dernier a décidé de financer deux nouvelles associations et de réapparaître, il y a trois ou quatre ans, sous la figure du dieu guerrier Guan, le jour du défilé. On pourrait voir dans ce jeu une manière d'amplifier la fête mais, selon les paroles de M. U., un responsable de l'organisation du défilé, l'installation du Guan Di soutenu par M. N., c'est daoluan «捣乱, faire des barricades », manifester une opposition totale. Une opposition qui s'exprime par le ballet des objets - la guerre des lions et celle des dragons, la salutation de Guang Di - mais qui s'évanouit à l'arrivée de Xuantianshangdi qui, en cet après-midi du Nouvel An, est le maître jamais ouvertement contesté du triangle de Choisy, son territoire. La bataille des icônes tente donc de retarder le retour chez lui du dieu avant la nuit, mais toujours sans succès. Pourquoi cette bataille a-t-elle cependant réussi à trouver sa place dans une journée qui semble si parfaitement contrôlée? Sans doute parce qu'elle manifeste à la perfection sa maîtrise du langage des objets animés. Mais elle ne sort jamais de ce répertoire par lequel s'expriment, sous une forme allégorique qui renvoie à la confrontation des dieux, les tensions internes au groupe dominant des organisateurs de la fête ${ }^{12}$.

\section{La culture sur la scène politique}

18 Le Nouvel An chinois dans son ensemble est une incessante circulation entre le dedans et le dehors, passant de la rue au temple, du temple aux commerces et aux restaurants ; sans oublier les appartements, où la fête familiale a parfois conservé, voire trouvé des formes traditionnelles. Pendant les deux semaines que durent les festivités, une série de manifestations obligées renouvellent l'alliance entre les "Asiatiques », présentés et pensés alors comme une " communauté », et les pouvoirs politiques locaux et nationaux. Il ne fait aucun doute que le Nouvel An chinois est la fête qui, à Paris, déclenche le plus de cérémonies officielles, qui sont aussi les plus spectaculaires et les plus riches de discours. De la petite salle de la paroisse de Saint-Hippolyte, où se retrouvent les Taïwanais autour de leur chargé d'affaires, jusqu'à l'Élysée présidentiel en passant par la mairie d'arrondissement et l'Hôtel de Ville de Paris où les élus républicains l'accueillent, le Nouvel An va à la rencontre des dirigeants politiques français. Il leur tient un langage particulier, à partir des mêmes objets animés. Parmi toutes les cérémonies officielles auxquelles j'ai assisté, j'ai choisi l'une des plus simples : celle qui s'est tenue à l'Hôtel de Ville en janvier 2012.

19 L'entrée se fait par la cour arrière. Les 1800 invités montent le grand escalier tout au long duquel des jeunes filles asiatiques en robe de la cour impériale les accueillent. Le grand salon est éclairé de tous ses lustres, d'une lumière assez douce car des projecteurs la teintent de rouge, la couleur dominante de la fête chinoise. La salle est pleine de gens debout, beaucoup d'Asiatiques mais presque autant d'Occidentaux, français bien sûr. Tous 
sont tournés vers une scène qui occupe toute la largeur du fond et se garnit peu à peu de personnages officiels en costume de ville, des hommes pour la plupart. On voit s'agiter les chefs du protocole qui installent tout ce monde dans un ordre déterminé, face au public, se souciant de mélanger notables français et chinois. Je reconnais plusieurs visages: Bertrand Delanoë, Anne Hidalgo et les représentants élus du XIII ${ }^{\mathrm{e}}$ arrondissement, des présidents d'association, des agents de l'ambassade de la République populaire de Chine. Aux côtés du maire de Paris, la petite silhouette et le visage impassible de M. Y. Sur la droite de l'estrade, un pupitre et un micro. Une femme chinoise vêtue de clair, présentatrice de la soirée, demande le silence en français et en chinois. Les bruits s'apaisent. Commencent les discours. Parmi la dizaine de cérémonies de ce genre que j'ai suivies, celle-ci est la plus sobre: deux orateurs seulement, le maire de Paris et le représentant de l'ambassade de la République populaire de Chine; le premier est traduit en chinois, le second alterne les deux langues. Deux discours équivalents et contrastés. Le maire introduit deux thèmes : l'importance des échanges culturels entre la France et la Chine (avec l'exemple récent d'une exposition d'art moderne et contemporain au musée Cernuschi, musée des Arts de l'Asie de la Ville de Paris) et la sérénité (mot répété à plusieurs reprises, qu'il préfère à celui de "sécurité ») à laquelle ont droit les Asiatiques de Belleville. Le représentant de l'ambassade reprend ces mêmes points. L'harmonie entre les deux populations est invoquée sans exemple, quant aux échanges ils sont illustrés par l'offre de deux pandas (dont il donne les noms) au zoo-parc de Beauval, dans le Loir-etCher. Il poursuit en donnant des chiffres précis sur les échanges économiques, dans le seul sens France-Chine où ils sont en "grande progression ». Les deux discours sont encadrés d'un éloge de la culture chinoise qui "participe à une rencontre de civilisations » et enrichit "la communauté française », selon le maire de Paris; qui est aimée et accueillie à l'Hôtel de Ville comme le montre la foule des invités, selon le représentant de l'ambassade. Bien sûr, les deux hommes coïncident dans leurs vœux de bonheur pour l'année du Dragon, signe du zodiaque chinois pour 2012.

fig. 8 Patrick Zachmann, Danse du lion, Paris, XIII ${ }^{\mathrm{e}}$ arrondissement, 1998.

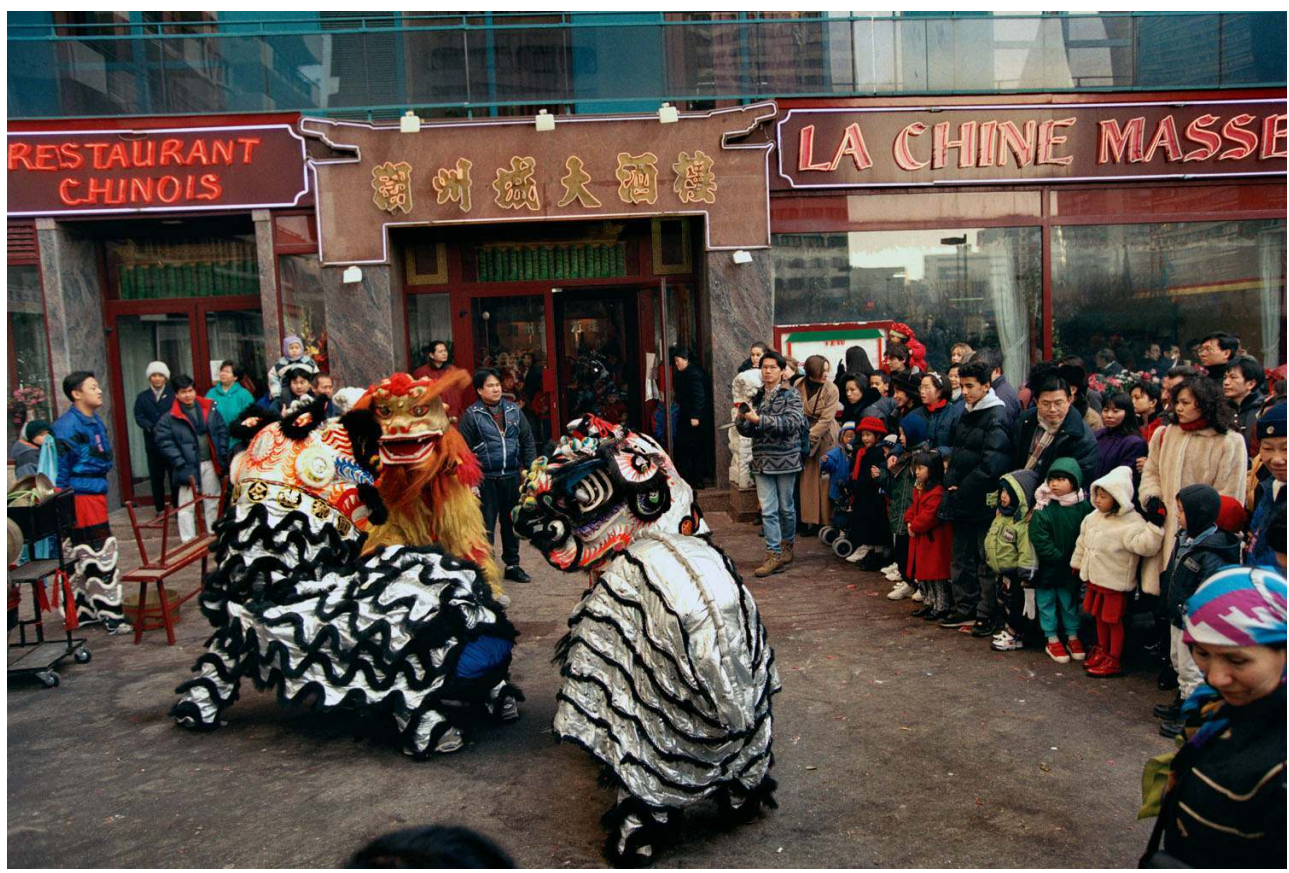

(c) Patrick Zachmann/Magnum Photos. 
Cette invocation de la culture justifie le spectacle présenté ensuite, très sobre comparé à d'autres, beaucoup plus surchargés, qu'il m'a été donné de voir. Alors que les officiels se retirent sur la droite de la scène, face au public, un mouvement soulève une masse colorée, jusqu'alors indistincte, au rythme, d'abord léger, des percussions. Suit le jeu acrobatique de trois lions: de véritables experts dont j'apprendrai qu'ils viennent tout exprès de Malaisie. Après leur démonstration, qui ne comporte, il faut le noter, aucune trace du scénario rituel de la danse du lion détaillée plus haut, un rang compact d'officiels s'interpose, tournant le dos au public, penchés sur une forme de toile argentée couverte d'écailles. Ils « réveillent » un dragon allongé sur le sol en traçant sur sa tête et son corps de petits cercles et des lignes à la peinture rouge comme on le fait devant le temple au départ du défilé, mais ici de façon assez désordonnée, il faut bien le dire. Le public ne voit rien de tous ces gestes confus, seuls ceux qui connaissent ce rite les devinent. Le dragon se redresse puis se déploie et occupe toute la scène que les personnalités quittent définitivement. Là encore, dans cet espace assez restreint, est proposée une extraordinaire démonstration du maniement d'une bête de toile, puis tous les personnages, le dragon et les trois lions, se mêlent en une sorte de ballet. Dragon et lion sont donnés ici comme les deux premières incarnations de la "culture chinoise ». Vient ensuite le second volet du spectacle, très différent. La scène est alors occupée par des garçons et des filles en costume qui représentent à la fois la Chine impériale et les diverses minorités contemporaines. Dans une première partie, sur fond de chant patriotique enregistré qui célèbre l'harmonie des ethnies vivant en Chine, les jeunes gens se déplacent de façon un peu mécanique, d'un pied sur l'autre. Dans un second temps, suivant un style à peu près identique, sont évoqués les héros de la dynastie Song. Tous ces jeunes acteurs participeront le dimanche suivant au défilé, ils sont là pour présenter leurs costumes sur une scène où, au lieu de marcher, ils sont figés ou piétinent sur place. Le spectacle fini, tout le monde se disperse dans les salles voisines pour partager un buffet où le champagne français arrose les petits fours franco-chinois.

21 Là encore, le cœur de ce qui est donné à voir tourne autour des mêmes objets. Objets d'un exotisme presque violent, détachés des conditions normales de la fête à laquelle on fait cependant allusion par quelques gestes (ondulations du dragon, sauts du lion). L'essentiel consiste, cependant, à montrer le tout début, le moment où ces objets prennent vie, s'animent : lion qui se soulève, dragon que l'on réveille, costumes portés par des corps qui bougent. Bien sûr, le contraste est absolu entre la rue du défilé et les salons luxueux de l'Hôtel de Ville. Mais, de l'avis des promoteurs du Nouvel An, la fête ne serait pas concevable si sa fonction politique (au sens le plus général) n'était pas clairement manifestée quelque part: dans ce mélange de discours et de gestes qui, autour de quelques objets emblématiques, célèbre la rencontre des cultures dans une société française unitaire. 


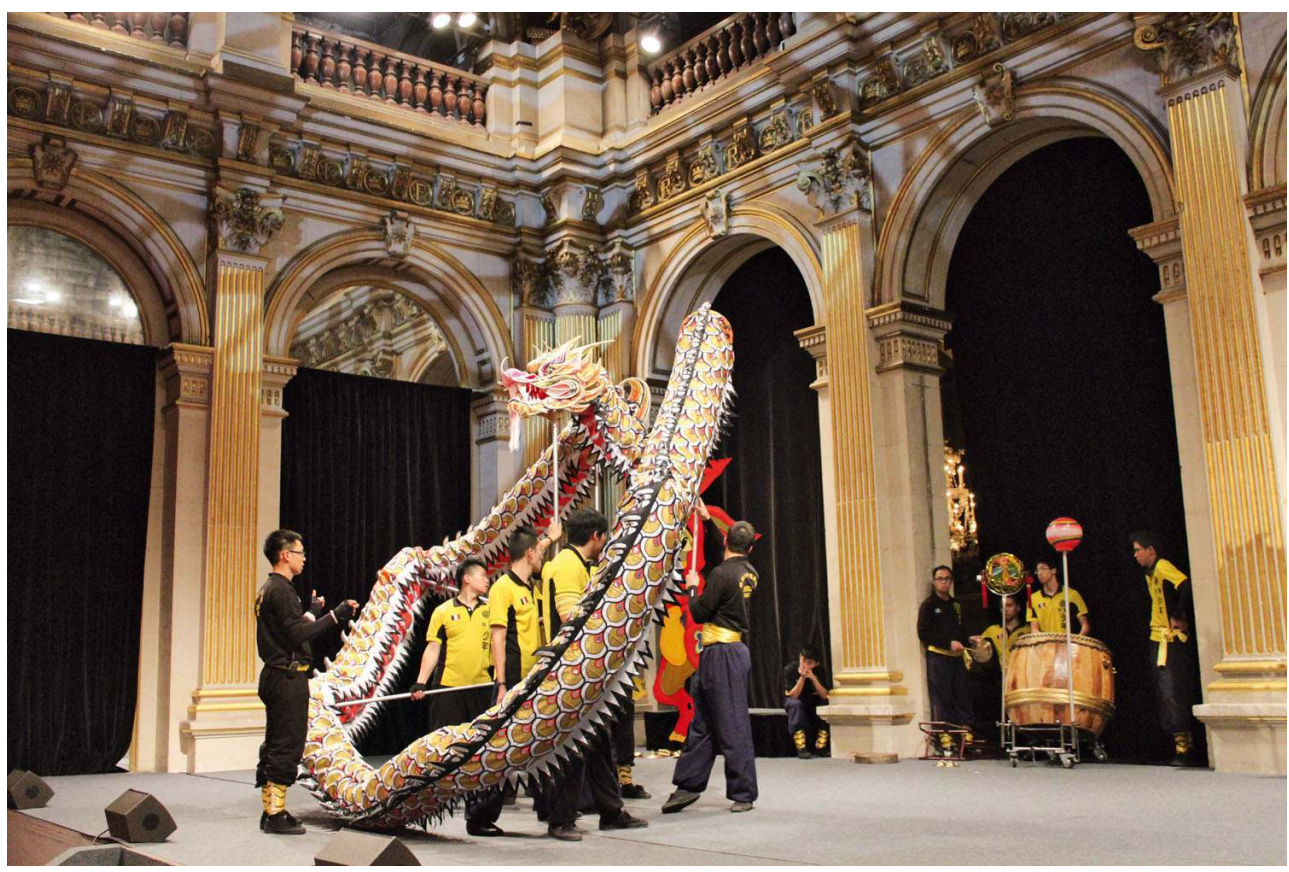

(c) Photo Jing Wang.

\section{Conclusion : instituer la culture chinoise, un processus profond}

Au cœur de la fête, dans ce temple d'où elle part depuis maintenant une vingtaine d'années, se dessine un processus de "création de la culture chinoise " dans une situation, celle d'une émigration convertie en diaspora, particulièrement propice à une telle genèse. Le chemin des objets nous en indique les supports, les pôles et les opérations. Je soulignerai simplement trois dimensions. La première concerne le travail collectif, dispersé et contradictoire, d'explicitation de cette entité nouvelle : " la culture chinoise ». De quoi est faite cette culture? Quelle est la vraie culture chinoise? Questions qui animent des débats multiples, formels et informels, publics et privés. Incontestablement, la culture chinoise se définit d'abord par un répertoire d'objets qui font plus largement partie, et c'est la deuxième dimension, d'une esthétisation de la fête publique. Mais la culture dans son ensemble correspond à un répertoire limité de pratiques qui retrouvent unité et continuité au sein d'un espace particulier, celui du temple. Là s'opère, troisième dimension du phénomène, la concentration de tous les objets et de toutes les conduites que nous avons observés sur les scènes que nous venons de décrire. On peut dire que le temple, doublé de son association où l'on apprend la langue, l'écriture, le chant, la cuisine, etc., où l'on expose toute l'année la tête du lion, où l'on garde les costumes, où se trouve même un petit musée des instruments de musique traditionnels, est un conservatoire improvisé de ce bric-à-brac que la fête met en mouvement.

Enfin, dernière observation, ce processus d'institution de la culture s'appuie, en situation migratoire, sur la relation entre le groupe migrant, la société d'accueil et le pays d'origine lorsque, comme la Chine actuelle, il manifeste un intérêt croissant pour sa diaspora. La question de la culture est le point de convergence et le langage partagé de ces trois 
ensembles. Je dirai même que la culture permet de dépasser les catégories politiques les mieux établies. Elle conduit toutes les autorités françaises à parler de "communauté chinoise et asiatique ", alors que le communautarisme est banni de la République. Elle réconcilie les autorités de la République populaire de Chine avec ces groupes d'émigrés longtemps dénoncés comme antinationaux car anticommunistes ${ }^{13}$. Et toujours, ce dialogue, qui s'invente et évolue en ce moment sous nos yeux, s'appuie sur l'ubiquité et la pluralité d'usages de quelques objets animés.

\section{BIBLIOGRAPHIE}

\section{Auguin, Estelle}

2004 «Le Nouvel An chinois à Paris : théâtre d'économies ethniques », Revue européenne des migrations internationales 20(3), « Routes et réseaux migratoires » : 75-87.

\section{Beraha, Richard (Dir.)}

2012 La Chine à Paris. Enquête au cœur d'un monde inconnu. Paris, Robert Laffont.

\section{Bonds, Alexandra B.}

2008 Beijing Opera Costumes. The visual communication of character and culture. Honolulu, University of Hawaii Press.

\section{Claveyrolas, Mathieu}

2003 Quand le temple prend vie. Atmosphère et dévotion à Bénarès. Paris, CNRS Éditions.

\section{Comentale, Christophe}

2004 Les Images porte-bonheur populaires en Chine. Paris, You-Feng Libraire Éditeur.

Costa-Lascoux, Jacqueline et Live, Yu-Sion

1995 Paris XIII ${ }^{e}$ lumières d'Asie. Paris, Autrement.

Fong, Mary

2000 « "Luck Talk" in celebrating the Chinese New Year ", Journal of Pragmatics (32)2 : 219-237.

Goossaert, Vincent

2000 Dans les temples de la Chine, histoire des cultes, vie des communautés. Paris, Albin Michel.

Guillon, Michèle et Tabaoda-Leonetti, Isabelle

1986 Le Triangle de Choisy : un quartier chinois à Paris. Paris, CIEMI-L'Harmattan.

\section{Hassoun, Jean-Pierre}

1986 « Les Chinois de Paris : minorité culturelle ou constellation ethnique ? ", Terrain 7, «Approches des communautés étrangères en France » : 34-44.

1992 « Pratiques religieuses et entreprises chinoises à Paris. Un paysage favorable ", Revue européenne des migrations internationales 8(3) :139-154. 
Hassoun, Jean-Pierre et Tan, Y.P.

1987 « La danse du lion dans le contexte parisien. Aspect d'un capital ethnique », actes du colloque international de le l'Association française des anthropologues (AFA). Paris, Éditions de l'Orstom : 340-346.

\section{Li, Minghuan}

1999 We Need Two Worlds. Chinese Immigrant Associations in a Western Society. Amsterdam, Amsterdam University Press.

\section{Raulin, Anne}

1986 Espaces marchands et expression communautaire : le XIII arrondissement de Paris, rapport à la Mission du patrimoine ethnologique. Paris, ministère de la Culture et de la Communication. 1991 « The aesthetic and sacred dimension of urban ecology : Paris' little Asia », Archives des sciences sociales des religions $73: 35-49$.

2006 L'ethnique est quotidien. Diasporas, marchés et cultures métropolitaines. Paris, L'Harmattan.

2008 « Utopie locale et laboratoire social : l'exemple du XIII ${ }^{\mathrm{e}}$ arrondissement de Paris », L'Année sociologique 58(1) : 47-70.

\section{Thunø, Mette (dir.)}

2007 Beyond Chinatown. New Chinese Migration and the Global Expansion of China. Copenhague, Nordic Institute of Asian Studies.

\section{Trémon, Anne-Christine}

2010 Chinois en Polynésie française. Migration, métissage, diaspora. Nanterre, Société d'ethnologie.

\section{Wong-Hee-Kam, Édith}

1993 "Les temples chinois de la Réunion ou la mémoire ancestrale sur une terre nouvelle ", in Jean Peyras (dir.), « Les monuments et la mémoire », Cahiers CRLH-CIRAOI 8 : 85-96.

\section{Yeh, Chiou-Ling}

2008 Making an American Festival: Chinese New Year in San Francisco's Chinatown. Berkeley, University of California Press.

\section{Yow, Cheun Hoe}

2007 « Detraditionalized and renewed Qiaoxiang areas: Case studies of Panyu and Wenzhou in the Reform period since 1978 ", in Thunø 2007 : 83-114.

\section{Zheng, Li-Hua}

1995 Les Chinois de Paris et leurs jeux de face. Paris, L'Harmattan.

\section{NOTES}

1. L'Asie-Europe Museum Network (Asemus) est un réseau, coordonné par la Commission européenne, réunissant des musées d'Europe et d'Asie et dont les principaux objectifs sont de promouvoir une meilleure compréhension entre les deux mondes par des collaborations, et de stimuler et faciliter l'utilisation et le partage des collections.

2. Voir les images rassemblées par Comentale 2004. 
3. C'est sur la sollicitation de Julie Trébault, responsable du développement du musée national d'Ethnologie aux Pays-Bas, que ces deux petits films ont été réalisés. Ils sont visibles sur http:// masterpieces.asemus.museum/videos.aspx, film I, "The Chinese Spring Festival in Paris » et http://www.youtube.com/watch?v=Iog0eoUvUP8\&feature=player_embedded, film II, «The collection of the Chinese Spring Festival of the musée du quai Branly in Paris ", http:// www.youtube.com/watch?v=4RjBIl779YU\& feature=player_embedded.

4. Voir à propos de ces costumes d'opéra le minutieux ouvrage d'Alexandra B. Bonds (2008).

5. Sur les migrations asiatiques à Paris voir Raulin 1986 et 2006 ; Hassoun 1986; Guillon et Tabaoda-Leonetti 1986 ; Costa-Lascoux et Live 1995.

6. Ce renversement a été également souligné par Li Minghuan dans son étude sur la migration chinoise aux Pays-Bas (1999). Mais, généralement, l'analyse de la production de la «culture chinoise » met l'accent sur la notion de revendication identitaire; voir par exemple les essais réunis par Mette Thunø (2007).

7. Ces premières sorties du lion en 1983 et 1984 ont, par chance, été vues et décrites par JeanPierre Hassoun et Y.P. Tan (1987) et Anne Raulin (1991 et 2008). Cette dernière a montré le rapport existant entre cette performance et les missionnaires chrétiens de la paroisse de SaintHippolyte.

8. Ma rapide évocation du temple s'est inspirée des travaux de Vincent Goossaert (2000) et Mathieu Claveyrolas (2003). Sur le rôle structurant du temple pour les émigrants chinois à la Réunion, voir Wong-Hee-Kam (1993) et, en Polynésie française, Trémon (2010 : 268-281).

9. Le travail sociologique d'Estelle Auguin (2004) a mis justement l'accent sur cet engagement des acteurs économiques.

10. Il faut, en effet, " réveiller » le dragon en traçant un point rouge sur son front et un cercle autour de ses yeux. Ce sont les officiels invités qui sont chargés de ce geste.

11. Sur cette migration très particulière et le système des tontines (hui), voir Yow 2007 et le volume sur le groupe parisien de Wenzhou (Beraha 2012).

12. Sur l'autocontrôle et la gestion des conflits chez les Asiatiques de Paris, voir Zheng Li-Hua 1995.

13. Le défilé du Nouvel An qui naît à San Francisco en février 1953, sous une forme qui va inspirer toute la diaspora chinoise, est clairement placé sous le signe d'une opposition à la Chine communiste (voir le beau livre de Chiou-Ling Yeh [2008]).

\section{RÉSUMÉS}

Les collections du musée du quai Branly consacrées à l'Asie contiennent des dizaines d'objets populaires, plutôt récents, venus de Chine et de la péninsule Indochinoise, qui tous évoquent les traditions du Nouvel An: papiers découpés, cartes de vœux, masque de lion, instruments à percussion... Ces mêmes objets sont présents, cette fois " animés » et chargés de sens, dans les fêtes du Nouvel An chinois - à la fois carnaval, procession religieuse et fête familiale - au cours desquelles les Asiatiques de Paris produisent et donnent en partage ce que tous leurs interlocuteurs politiques appellent leur «culture ». Malgré le caractère très public et officiel du Nouvel An, le cœur de son organisation - qui se trouve dans un temple - reste cependant méconnu de bien des acteurs costumés comme des spectateurs ordinaires. L'enquête éclaire la 
face invisible de ce monde et accède à son noyau polémique en suivant toujours la piste des objets sans qui la fête et le rite ne seraient pas ce qu'ils sont.

The musée du quai Branly's Asian collections contain scores of relatively recent objects from China and Indochina associated with New Year celebrations: paper cut-outs, greetings cards, lion masks, percussion instruments, etc. We find these same objects, but this time very much " alive ", in Chinese New Year celebrations in Paris' Asian neighbourhoods. These celebrations (which are simultaneously carnivals, religious processions and family festivities) allow Parisian Asians to reproduce and share what their political and institutional interlocutors unfailingly refer to as their "culture". Despite its highly official and public face, the New Year's organisational underpinnings remain mysterious for many participants and spectators. This article seeks to uncover these underpinnings by following the trace of those objects that make the festivities what they are.

\section{INDEX}

Keywords : Chinese New Year, musée du quai Branly, Chinese immigration, celebrations, objects Mots-clés : Nouvel An chinois, musée du quai Branly, immigration chinoise, fête, objets

\section{AUTEUR}

\section{JING WANG}

Lahic -CNRS-Ehess

Chinafrance2004@yahoo.fr 